\title{
Anesthetic Management of a Rare Case of Type 2 Arnold- Chiari Malformation with Hydrocephalus, Lumbar Myelomeningocele and Thoracolumbar Scoliosis
}

\author{
Anand John ${ }^{1}$, Yashashwini Katari ${ }^{2}$, Venkatesh Murthy ${ }^{3}$, Hiremathada Sahajananda ${ }^{4}$
}

\begin{abstract}
Arnold-Chiari malformation is a group of deformities seen in the hindbrain that is cerebellum, pons, and medulla oblongata. Based on the morphology of the malformations as seen radiologically or during an autopsy, Chiari II includes brainstem, fourth ventricle, and greater than $5 \mathrm{~mm}$ descent of the caudal tip of cerebellar tonsils past the foramen magnum with spina bifida.

In the present case, a report of anesthetic management of a 29 -year-old school clerk presented with hydrocephalus and myelomeningocele and MR imaging revealed herniation of cerebellum and medulla through foramen magnum, hence, confirming it to be a case of type II Chiari malformation posted for ventriculoperitoneal shunting and foramen magnum decompression.
\end{abstract}

Keywords: Arnold-Chiari malformations, Foramen magnum decompression, General anesthesia, Myelomeningocele.

The Journal of Medical Sciences (2019): 10.5005/jp-journals-10045-00104

\section{INTRODUCTION}

Arnold-Chiari malformation is a developmental malformation characterized by downward displacement of cerebellar tonsils into the spinal canal due to reduced capacity of the posterior fossa. ${ }^{1}$

The anatomical variations attributing to the Arnold-Chiari malformation is due to the failure of the pontine flexure to form normally from the 28th to 29th day of gestation which causes the elongation of the brainstem. These structural deformities lead to blockage in the flow of cerebrospinal fluid, producing an embryological hydrocephalus. ${ }^{2}$

Arnold-Chiari malformation type 2 (ACM2) is also called as classic Chiari malformation. It is less common. In type II Chiari malformation, there is caudal descent of cerebellar tonsils and the vermis into the spinal canal along with the brainstem and fourth ventricle. Type II Chiari malformation is usually associated with myelomeningocele. Hydrocephalus is seen in $90 \%$ of cases. Symptoms are due to dysfunction of brain cells and lower cranial nerves. Myelomeningocele results in the partial or complete paralysis of the area below the spinal opening. Due to the severity, type II Chiari malformation patients become symptomatic in infancy or early childhood. ${ }^{2}$

The myelomeningoceles may occur in any part of the spine but it is predominately observed in the lumbosacral region, the last region of the neural tube to fuse, with thoracolumbar lesions being less typical. $^{3}$

Here, we present an anesthetic management of a case of ACM2 with hydrocephalus with lumbar myelomeningocele and thoracolumbar scoliosis.

\section{Case Report}

A 29-year-old school clerk came with complaints of paresthesia of all four limbs and neck since 8 months. In addition to his neurological symptoms, he had scoliosis of thoracolumbar spine with convexity to right. His past medical history revealed that he has undergone lumbar myelomeningocele repair during childhood. A hypertrophied scar was present in L2-L3 levels measuring about $\overline{{ }^{1-4} \text { Department of Anesthesiology, RajaRajeswari Medical College \& }}$ Hospital, Mysore Road, Bengaluru, Karnataka, India

Corresponding Author: Anand John, Department of Anesthesiology, RajaRajeswari Medical College \& Hospital, Mysore Road, Bengaluru, Karnataka, India, Phone: +919482088020, e-mail: anandjohn13@ gmail.com

How to cite this article: John A, Katari Y, Murthy V, Sahajananda $\mathrm{H}$. Anesthetic Management of a Rare Case of Type 2 Arnold-Chiari Malformation with Hydrocephalus, Lumbar Myelomeningocele and Thoracolumbar Scoliosis. J Med Sci 2019;5(1):14-16.

Source of support: Nil

Conflict of interest: None

$4 \times 4 \mathrm{~cm}$. Left scapula was prominent. His room air saturation was $91 \%$. Airway examinations showed an interincisor gap of $3 \mathrm{~cm}$, Mallampati class II, and severe limitation of cervical spine mobilization. The patient's arterial blood gas (ABG) report findings were $\mathrm{pH} 7.39, \mathrm{pO}_{2}$ of $62.7 \mathrm{~mm} \mathrm{Hg}, \mathrm{pCO}_{2}$ of $36.3 \mathrm{~mm} \mathrm{Hg}_{1} \mathrm{HCO}_{3}$ of 21.6, and $\mathrm{SO}_{2}$ of $91.3 \%$. His hemoglobin was $16.9 \mathrm{~g} \%$, hematocrit $53.8 \%$, white blood cell $9,900 / \mathrm{mm}^{3}$, normal differential count, and platelets $230,000 / \mathrm{mm}^{3}$. Chest X-ray revealed scoliosis in the thoracolumbar spine with convexity to right. The liver function test was within the normal range. Magnetic resonance imaging (MRI) lumbar spine with whole spine screening showed myelomeningocele at L3-L4 levels with herniation of cerebellum and medulla, L3 hemivertebra with parietal block L3-L4 vertebra, and syrinx in spinal cord at C2-C7 levels (Fig. 1). A right ventriculoperitoneal shunt with foramen magnum decompression was planned for the patient. General anesthesia was planned for this patient.

The patient was shifted to the operating theatre in a trolley. In the operating theater, the patient was monitored using electrocardiogram (ECG), pulsoximeter, noninvasive blood pressure and invasive blood pressure, temperature probe, and capnography. His baseline vitals were: heart rate, $82 /$ minute; blood pressure, $114 / 84 \mathrm{~mm} \mathrm{Hg}$; and $\mathrm{SpO}_{2}, 91 \%$ with room air and $100 \%$ with $6 \mathrm{~L} /$ minute oxygen.

(0) The Author(s). 2019 Open Access This article is distributed under the terms of the Creative Commons Attribution 4.0 International License (https://creativecommons. org/licenses/by-nc/4.0/), which permits unrestricted use, distribution, and non-commercial reproduction in any medium, provided you give appropriate credit to the original author(s) and the source, provide a link to the Creative Commons license, and indicate if changes were made. The Creative Commons Public Domain Dedication waiver (http://creativecommons.org/publicdomain/zero/1.0/) applies to the data made available in this article, unless otherwise stated. 


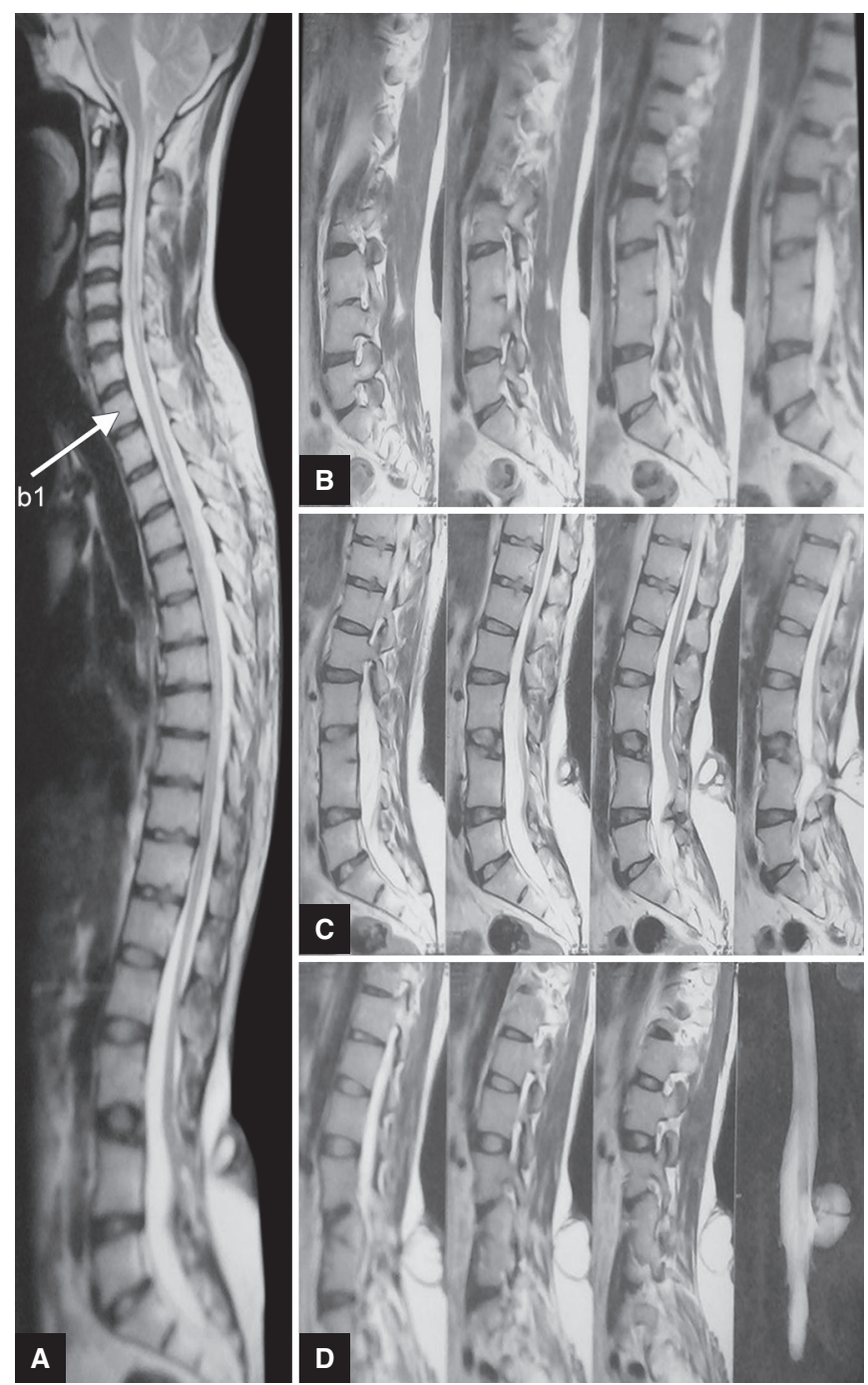

Figs $1 \mathrm{~A}$ to $\mathrm{D}$ : $\mathrm{MRI}$ spine showing Chiari malformation with herniation of tonsils below foramen magnum with myelomeningocele at the lumbar region

16G IV cannula was secured in the left hand. The patient was premedicated with injection glycopyrrolate $0.2 \mathrm{mg} \mathrm{IV}$ and injection midazolam $1 \mathrm{mg}$ IV. The patient was preoxygenated with $100 \%$ oxygen for 3 minutes. General anesthesia was induced with injection propofol $100 \mathrm{mg}$ IV and injection fentanyl $100 \mathrm{mg}$ IV. After injection vecuronium $6 \mathrm{mg}$, the patient was intubated with a cuffed flexometallic endotracheal tube of size $8.5 \mathrm{~mm}$ using VividTrac videolaryngoscope using manual-in-line-stabilization. Bilateral air entry was checked and the tube was fixed at $19 \mathrm{~cm}$. The arterial line was secured in the left radial artery. The peripherally inserted central venous catheter (PICC) line was secured in the right cubital region. Anesthesia maintenance was carried out by using isoflurane along with oxygen and nitrous oxide and infusion of injection dexmedetomidine $0.25 \mathrm{mg} / \mathrm{kg}$. Injection paracetamol $1 \mathrm{~g}$ was given IV intraoperatively. Muscle relaxation was continued with injection vecuronium $1 \mathrm{mg}$ bolus top-up doses IV. Normocapnea and normothermia were maintained throughout the procedure.

The patient was placed in the supine position initially for performing right ventriculoperitoneal shunt, followed by the prone position for foramen magnum decompression. The patient remained hemodynamically stable throughout the procedure.
Infusion injection dexmedetomidine was gradually tapered and stopped. The inhalation agents were cut off at the end of the procedure and the neuromuscular blockade was reversed using injection glycopyrrolate $1.1 \mathrm{mg}$ and injection neostigmine $2.75 \mathrm{mg}$. The patient was extubated after the extubation criterion was met.

The patient was shifted to surgical intensive care unit (SICU) postoperatively. The patient was shifted to the surgical ward on the second postoperative day and was discharged from the hospital on the seventh postoperative day.

\section{Discussion}

There are very few case reports on anesthetic management in patients with $\mathrm{ACM} 2$, hydrocephalus with myelomeningocele, and here we report our case with a successful outcome.

Arnold-Chiari malformation is a group of deformities seen in the hindbrain that is cerebellum, pons, and medulla oblongata. Based on the morphology of the malformations as seen radiologically or during an autopsy, Chiari II includes brainstem, fourth ventricle, and greater than $5 \mathrm{~mm}$ descent of the caudal tip of cerebellar tonsils past the foramen magnum with spina bifida. ${ }^{4}$

According to Stevenson, approximately one-third of the patients with Chiari II malformation show signs and symptoms of brainstem compression. ${ }^{5}$

Gammal et al. stated that myelomeningocele is associated with type II Chiari malformation almost in all cases. However, the vice versa is not always true. ${ }^{6}$

According to Rauzzino et al., hydrocephalus is seen in $90 \%$ of the cases and the ventricles are seen asymmetrically. ${ }^{7}$

The patients with $A C M 2$, hydrocephalus with myelomeningocele scheduled for ventriculoperitoneal shunting, and foramen magnum decompression present with some degree of neurologic involvement, which indicates significant compression of the neural elements. In patients with $\mathrm{ACM} 2$, hydrocephalus with myelomeningocele, there have been no studies previously on the choice of any particular anesthetic agents that are indicated and contraindicated. However, anesthetic management should begin with a careful preanesthetic check regarding the medical history, a complete physical examination of the patient's airway, respiratory, cardiovascular, and neurologic systems to exclude possible associated comorbidity. Patients with these conditions can pose various challenges to the anesthesiologists regarding positioning and the anesthetic management.

In this patient, in view of severe limitation of cervical spine mobilization and syrinx in the spinal cord at the C2-C7 level, VividTrac videolaryngoscopy was used and the patient was intubated in the neutral position. During extubation, careful planning should be done. Need for postoperative ventilatory support with slow weaning is indicated in patients with a pronounced brainstem compression.

Autonomic function should be evaluated in patients with significant brainstem involvement. ${ }^{8}$ In this case, there was no autonomic dysfunction; hence, on changing the position from supine to prone, there was no significant hemodynamic instability.

\section{ConCLUSION}

In conclusion, ACM2 and its associated abnormalities pose various anesthetic challenges and the proper anesthetic management has not yet been established. Optimal patient outcome will be improved with an interdisciplinary team management including anesthesiology, neurology, and neurosurgery. 


\section{ACKnOWLedgments}

The authors would like to thank the neurosurgeons Dr Dibanth Chakraborthy, Dr Sabyasachi Basu, and Dr Keshav for allowing us to publish this case report.

\section{References}

1. Balaji $K$, Pratap $R$, et al. Anaesthetic management in a patient with Arnold-Chiari malformation type I and Syringomyelia. J Evol Med Dent Sci 2013;2(17):2908-2911.

2. Hassan A, Yaseen S, et al. Arnold-Chiari Malformation: Anatomical Variations and Latest Embryological Perspective. Review of Literature. Int J Contemp Med Res 2016;3(5):1489-1491.
3. Kural C, Solmaz I, et al. Evaluation and management of lumbosacral myelomeningoceles in children. Eurasian J Med 2015;47(3):174. DOI: 10.5152/eurasianjmed.2015.138.

4. Hidalgo JA, Varacallo M. Arnold-Chiari Malformation. Statpearls, Copyright $\odot$ 2019, StatPearls Publishing LLC.

5. Stevenson KL. Chiari type II malformation: past, present and future. Neurosurg Focus 2004 Feb 15;16(2):E5.

6. Gammal EL, Mark EK, et al. MR imaging of Chiari ll malformation. AJR Am J Roentgenol 1988;150:163-170. DOI: 10.2214/ajr.150.1.163

7. Rauzzino M, Oakes WJ. Chiari II malformation and syringomyelia. Neurosurg Clin N Am 1995;6:293-309.

8. Kim TY, Lee C, et al. Anesthetic management of a patient with ArnoldChiari malformation type I with associated syringomyelia: A case report. Reg Anesth Pain Med 2012;7(2):166-169. 